\title{
Possibilities of neighborhood evacuation within a district in the event of a large-scale flood in a low-lying area: A case study of Shinden district in Tokyo
}

\author{
Hitoshi Nakamura ${ }^{1, a}$ \\ ${ }^{1}$ Shibaura Institute of Technology, 307 Fukasaku, Minuma-ku, Saitama-shi, Saitama, Japan
}

\begin{abstract}
The objective of this study is to examine the possibilities of neighborhood evacuation within a district in the event of a large-scale flood in a low-lying area, through a case study of Shinden district in Tokyo. Shinden district is highly vulnerable to flooding because it is surrounded by two large rivers, namely, the Arakawa River and Sumida River. In a part of the district, however, there is a large-scale super levee area that is apparently used as a safe evacuation area. In conclusion, in the event that the Arakawa River in Shinden district is breached, the number of estimated potential evacuees at night exceeds the number of estimated night-time evacuees, and the number of estimated potential evacuees in the daytime exceeds the number of estimated daytime evacuees. Therefore, it is possible for people in an inundated area to evacuate to safe places in the neighborhood on the condition that an appropriate evacuation system is established, taking into consideration possible routes to the evacuation areas and the possibility of making use of private apartments or other private buildings as evacuation spaces. In particular, the super levee project has contributed to the creation of a large-scale neighborhood evacuation area.
\end{abstract}

\section{Background}

\subsection{Evacuation in the event of a large-scale flood in Tokyo}

The eastern part of Tokyo, Japan, consists of a largescale, low-lying area where the mean ground level is lower than sea level (Figure 1). Because a large part of this low-lying area is occupied by districts that are densely built-up with old, low-rise wooden buildings, the number of high-rise buildings does not seem to be sufficient for their use as evacuation spaces.

The revisions to the flood prevention law in 2005 required municipalities to publish flood hazard maps that highlighted the flood hazards and evacuation areas. Depending on river water levels, each municipality is obligated to issue evacuation advisories or orders based on their respective hazard maps. However, municipalities in low-lying areas are finding it difficult to develop comprehensive hazard maps as there are insufficient safe upland evacuation areas when there are large-scale floods; thus, many local residents may need to be evacuated to areas outside the municipality.

According to a report by the expert committee in the Cabinet Office for considering measures against a largescale flood [1], in the event of a large-scale flood in a low-lying area, those who face the risks of losing their lives or staying in an isolated evacuation area for a long time in poor living conditions have to be evacuated to

\footnotetext{
${ }^{\mathrm{a}}$ Corresponding author: nakamu-h@shibaura-it.ac.jp
}

areas that are a long distance away from the inundated areas. However, it is estimated that a massive number of people would have to evacuate, and there are many disabled people who cannot evacuate by themselves. Therefore, instead of a long-distance evacuation, an evacuation system that is more practical should be examined, taking into consideration the specific features of the hazards and the response capabilities of each district.

The Cabinet Office pointed out that the evacuation methods described in the existing hazard map of each municipality in a low-lying area will not be effective in the case of a delay in evacuation caused by public transport congestion, or if the number of evacuees exceeds the capacity of each designated evacuation area [1]. It is also possible that each evacuee will not have enough time to reach an evacuation area due to delays in public announcements advising people to evacuate or delays in evacuation actions by those who need to evacuate. And many residents do not heed evacuation advisories as they believe that the formal safe evacuation areas are in public facilities within the district such as elementary or junior high schools [2]; this is mainly because they are used as refuges when there is a largescale earthquake, even though they would be inundated in the event of a large-scale flood.

In order to cope with these situations, the Cabinet Office stated that it is necessary to examine other evacuation methods, such as temporarily evacuating an evacuee to the upper floor of a school building or an 
upland area created by a large-scale, high-standard upland levee, called a "super levee," in the neighborhood [1]. After that, depending on the situation, the evacuee would then move to a safer area far away from the temporary evacuation shelter.

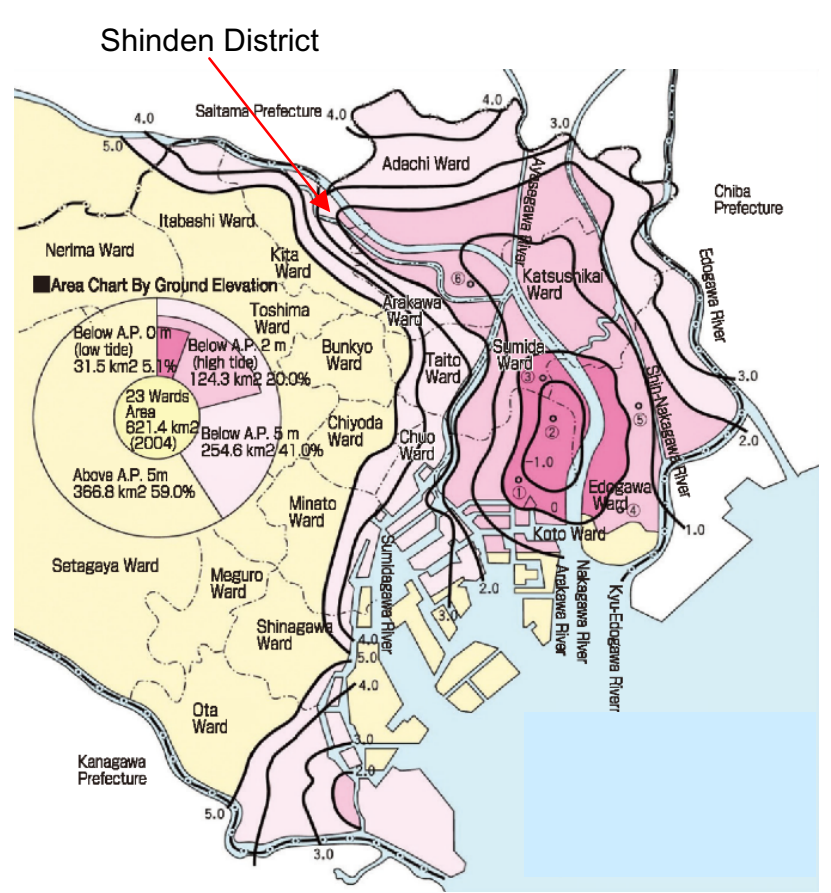

Area below low tide sea level: $31.5 \mathrm{~km}^{2}$

Area below high tide sea level: $124.3 \mathrm{~km}^{2}$

Area below design tidal sea level: $254.6 \mathrm{~km}^{2}$

Figure 1. Low-lying area in Tokyo [3].

\subsection{Super levee}

A super levee is a high-standard river embankment with a broad width that can withstand the pressure of water even if it overflows. A high-standard levee improvement project (a super levee project) was started in 1987 along six large rivers in Tokyo and Osaka, i.e., Tonegawa, Edogawa, Arakawa, Tamagawa, Yodogawa, and Yamatogawa.

Conceptually, a super levee is about 30 times as wide as it is high, so that even if the water overflows, it will not breach the levee because it will flow slowly across the levee's surface. Each super levee actually would not be overtopped in the event of a large-scale flood, because the height of super levees is the same as the other normal levees that would be breached beforehand. A conventional dike can be transformed into a super levee by increasing its height and broadening its slope. The ownership of the land of a super levee special development zone remains unchanged after the project. This special zone can be for urban land use [4].

In comparison with a conventional dike, a super levee has various advantages. These include ground improvement, open spaces that can be used as evacuation areas, a gentle slope, and easier access to the river, as well as a better landscape and living environment. However, the creation zone of a super levee project will exist discontinuously for an extended period of time because it is often promoted in conjunction with an urban development project along the river. The difficulty of consensus building, project prolongation, large-scale compensation for removal, and effects on the surroundings, including sunshine exposure, are the main disincentives for the project.

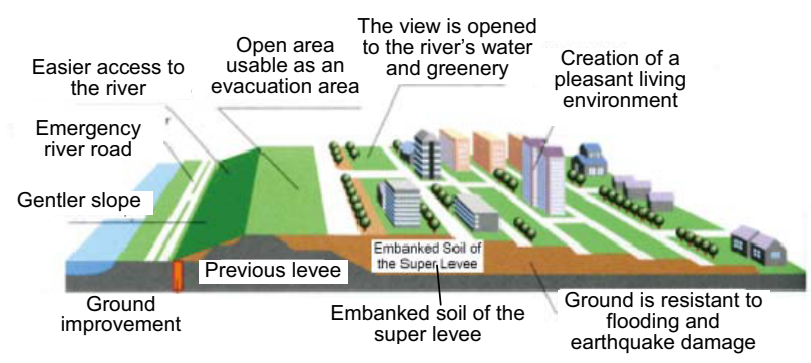

Figure 2. Concept of a super levee [4, 5].

According to the 2011 report of the Board of Audit, as of the end of March 2010, of the districts that had implemented projects (123 districts), the total length was $50.6 \mathrm{~km}$ and the implementation rate was $5.8 \%$ of the total length of the project zone $(872.6 \mathrm{~km})$. The project priority zone is $223.8 \mathrm{~km}$, but the total length of where districts implemented the project was $27.7 \mathrm{~km} \mathrm{(59}$ districts): an implementation rate of $12.4 \%$. The national budget screening system of 2010 estimated the total project expense of high-standard levees for the past 24 years to be 694 billion yen. In other words, when projects are promoted at the same pace, approximately 400 years and a total project cost of 12 trillion yen are necessary to complete the total project zone. Therefore, a decision was made to abandon the super levee project in the national budget screening system of 2010 .

Following the budget screening decision in 2010, the Ministry of Land, Infrastructure, Transport and Tourism (MLIT) undertook a significant review of its policy in August 2011. According to this new policy, the creation zone for super levees will be narrowed down to low-lying areas or densely built-up areas in large cities where serious human damage is more likely to be incurred in the event of a large-scale flood [5].

\section{Objective and method}

The objective of this study is to examine the possibilities of neighborhood evacuation within a district in the event of a large-scale flood in a low-lying area, through a case study of Shinden district in Tokyo.

Shinden district is highly vulnerable to flooding because it is surrounded by two large rivers, namely, the Arakawa River and Sumida River. In a part of the district, however, there is a large-scale super levee area that is apparently used as a safe evacuation area [6].

For the purpose of this study, field surveys were first conducted to determine land use, building use, and 
number of stories of each building in the district. In addition, the area of each parcel and the floor area of each building were measured using the 1:2,500 topographic GIS map. Then, the population of residents and workers either in the daytime or at night in the district was estimated based on the existing statistical data. The potential number of evacuees and the potential capacity of each possible evacuation area in the district were estimated based on certain assumptions.

\section{Shinden district}

Shinden district is located in the southwestern area of Adachi ward in Tokyo (Figure 1). It includes a part of the low-lying area surrounded by the Arakawa River and Sumida River (Figure 3). It comprises Shinden 1-chome, 2-chome, and 3-chome on the basis of the address unit "chome." The total area of the Shinden district is 147 hectares. According to the national census of 2010, the night-time population is 14,291 . The population density is 97 people per hectare. The population aging rate is $16.2 \%$.

Land use in the Shinden district is mixed, with lowrise detached houses, public apartments, private high-rise apartments, industrial facilities, warehouses, and so on. A super levee located in the western part of Shinden district occupies about two-thirds of the 3-chome area (Figure 4/3). This super levee area was completed in 2012 on the former site of a large-scale industrial facility, which moved out in the early 1990 s.

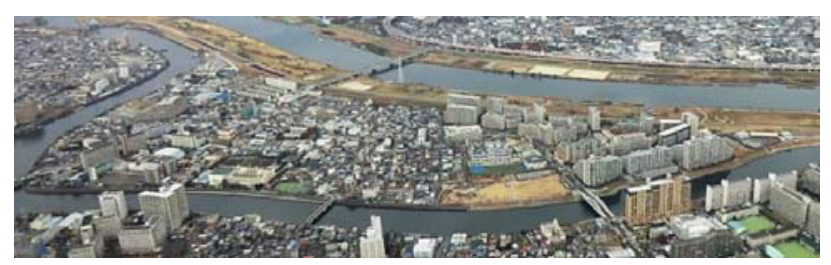

Figure 3. Shinden District.

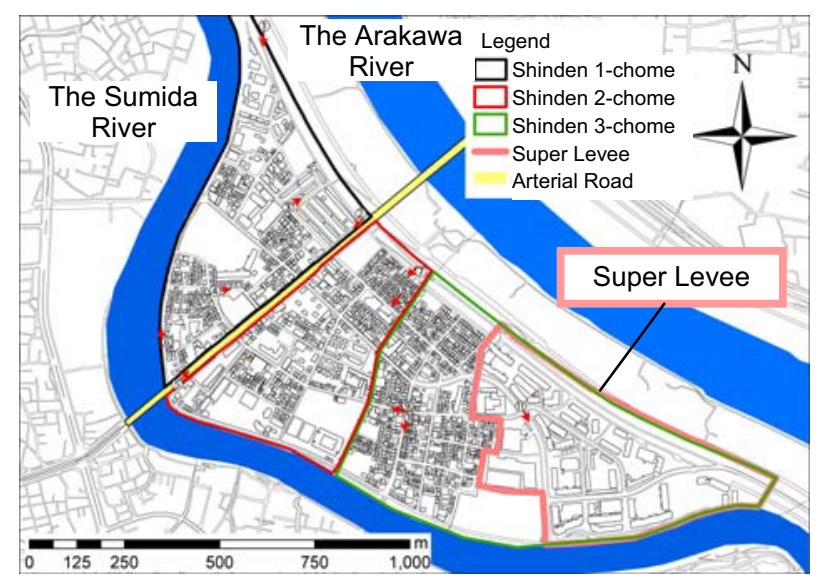

Figure 4. Super Levee in Shinden District.

The area of the super levee is 24.6 hectares. Its length is about $1,360 \mathrm{~m}$, and its mean width is about $181 \mathrm{~m}$. The main land use is the agglomeration of middle-rise and high-rise apartments. It includes some public facilities, such as an elementary school, junior high school, sewerage facility, and a fire station. It also includes commercial facilities, such as a superstore.

A flood hazard map of the Arakawa River was made by each municipality along the river using the estimated inundation area data of the Arakawa-Karyu River Office, based on the assumption that the probability of precipitation is once in 200 years. The hazard map of each municipality indicates not only the extension of inundated areas and the depth of inundation but also the evacuation areas in the event of flooding (Figure 5, 6).

The flood hazard map for the Arakawa River published by the Adachi ward in Tokyo recommends that people living or working in the Shinden district temporarily evacuate to the upper floors of a high school building (Figure 5) when an evacuation advisory is issued. Subsequently, depending on the situation, the evacuees are advised to move to upland areas outside the district. However, these upland areas are located in adjacent municipalities, so people have to evacuate before the flood event by crossing the bridge over the river.

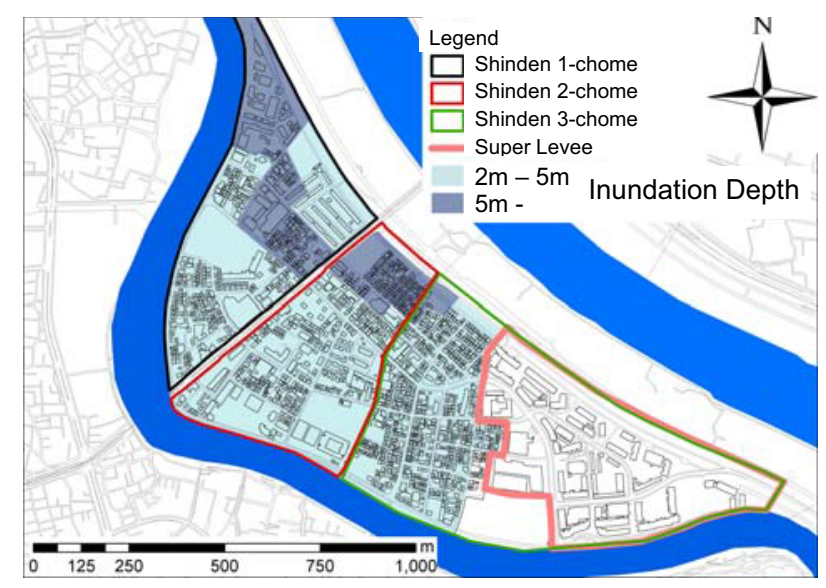

Figure 5. Flood Hazard Map in Shinden District.

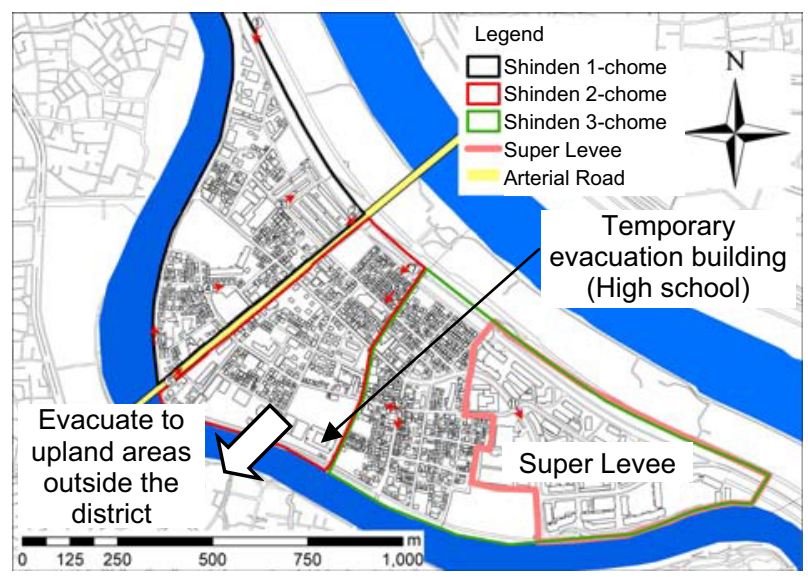

Figure 6. Orientation of safety evacuation areas in Shinden District.

An interview survey of Adachi ward in December 2015 confirmed that the official evacuation policy is to 
evacuate to upland areas located in other adjacent municipalities and the possible evacuation areas and methods have been examined in collaboration with adjacent municipalities. Although super levee areas are designated evacuation areas for the large-scale fires that follow an earthquake, they are thought to be unsuitable as evacuation areas in large-scale floods because they become isolated after inundation.

In Shinden district, Adachi ward has also made an agreement with the public or semi-public apartments in the super levee area in order to use common spaces in each building for the temporary evacuation of residents who live in inundated buildings. However, these agreements have not been made with middle- or high-rise private apartments, which would be temporary evacuation spaces in the district.

\section{Estimations}

\subsection{Inundated buildings}

According to a field survey conducted in 2015, the total number of buildings in the district is 1,874 . Detached houses make up $66 \%$ of all buildings. Apartments and office buildings account for $11 \%$ and $9 \%$, respectively. Two-story buildings make up $67 \%$ of all buildings. Three- and one-story buildings account for $21 \%$ and $6 \%$, respectively (Figure 7 ).

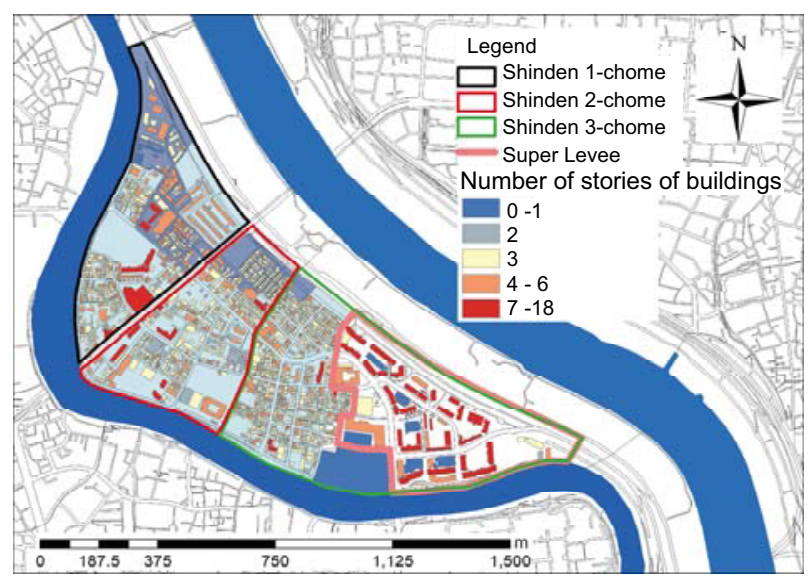

Figure 7. Number of stories of buildings in Shinden district.

Based on the inundation depths described in the hazard map in the event that the Arakawa River is breached (Figure 4), 17\% of the buildings will be inundated to a level exceeding $5 \mathrm{~m}$, while $57 \%$ of the buildings will be inundated to a level exceeding $2 \mathrm{~m}$ and below $5 \mathrm{~m}$. In total, $74 \%(1,386$ out of 1,874$)$ of the buildings in the district will be completely inundated. Detached houses that will be completely inundated account for $71 \%$ of all buildings completely inundated. Office buildings and apartments that are completely inundated account for $9 \%$ and $5 \%$, respectively.

\subsection{Evacuees}

\subsubsection{Night-time evacuees}

The total number of night-time evacuees, in the event that the Arakawa River is breached, has been estimated based on the following assumption. The number of nighttime evacuees is estimated by the "number of inundated housing units" multiplied by the "average household size based on building types" multiplied by the "average vacancy rate."

The number of inundated housing units is estimated by the number of completely inundated detached houses, completely inundated floors of apartments, and completely inundated mixed-used buildings with residential and commercial. Based on this estimation, the number of inundated housing units is estimated to be 2,160 in total. The inundated housing units in detached houses, apartments, and mixed-used buildings with residential and commercial account for $46 \%, 52 \%$, and $3 \%$, respectively.

The average household size, based on building types, is estimated using data from the 2010 national census. For detached houses and mixed-used buildings with residential and commercial, 2.6, 2.4, and 2.5 represent the average household size in 1-chome, 2-chome, and 3chome, respectively. For apartments, 1.5, 1.6, and 1.9 represent the average household size in 1-chome, 2chome, and 3-chome, respectively.

The average vacancy rate is estimated from the data for the Adachi ward area from the 2013 housing and land survey. The average vacancy rates of detached houses and apartments are $5.5 \%$ and $18.8 \%$, respectively.

Based on the calculation described above, the total number of night-time evacuees is estimated to be 3,905. The estimated number of evacuees in the inundated detached houses account for $60 \%$ of total night-time evacuees. Estimated evacuees in the inundated apartments account for $37 \%$.

\subsubsection{Daytime evacuees}

The number of daytime evacuees is estimated based on the following three-step calculation.

In the first step, the number of evacuees in inundated detached houses, apartments, and mixed-use buildings with residential and commercial in the daytime is estimated as the "total number of night-time evacuees" multiplied by the "percentage of the non-working population in the daytime (except students) out of the total night-time population." The ratio of the nonworking population in the daytime (except students) to the total night-time population is estimated using data from the 2010 national census. Detached houses, apartments, and mixed-use buildings with residential and commercial account for $29.5 \%, 28.8 \%$, and $21.6 \%$ of the total, respectively. Based on this estimation, the evacuees in inundated detached houses, apartments, and mixed-use buildings with residential and commercial in the daytime are estimated to be 688,212 , and 27 , respectively. 
In the second step, the number of evacuees in inundated school buildings is calculated as the "total number of people below 20 years old in the district" multiplied by the "percentage of the total inundated floor area out of the total floor area of school buildings in the district." This calculation consists of two stages. The first stage is to calculate the number of students in each school or nursery to determine the total number of people below 5 years old $(1,143)$ in nurseries, people from 5 to less than 15 years old $(1,190)$ in elementary and junior high school, and people 15 to 20 years old (715) in senior high school, based on the floor area of each school building. The second stage is to estimate the evacuees based on the percentage of the total inundated floor area out of the total floor area of school buildings, which account for $70.9 \%$ in 2-chome and 3.5\% in 3-chome. As for evacuees from nurseries, the average percentage $(32 \%)$ of nursery utilization for each household that has children younger than 5 years old is taken into consideration based on the survey by the Ministry of Health, Labor and Welfare (2010). Based on this estimation, the evacuees in inundated school buildings in the daytime are estimated to number 179 .

The third stage is that the number of evacuees in other inundated buildings is estimated as the "total number of workers based on industrial types in the district" multiplied by the "ratio of the total inundated floor area to the total floor area of buildings based on industrial types in the district." This calculation has two stages: the first is to calculate the number of evacuees for each industrial type; and the second is to sum up the evacuees estimated in the first stage. Based on this calculation, the daytime evacuees in, respectively, inundated commercial buildings (461), office buildings (178), cultural facilities (87), religious buildings (31), industrial buildings (583), transportation facilities (69), and medical facilities (30) are estimated.

Based on the three-step calculation described above, the total number of daytime evacuees is estimated to be 2,535. Estimated evacuees in the detached houses, industrial buildings, commercial buildings, schools, and office buildings account for $27 \%, 23 \%, 18 \%, 7 \%$, and $7 \%$, respectively, of the total daytime evacuees.

\subsection{Potential evacuees}

Possible evacuation spaces are calculated based on the assumption shown in Table 1: the possible percentage of evacuation spaces out of the total floor area, based on building use. These ratios are induced by rule of thumb, taking into consideration normal building design. Parks or other open spaces are not considered appropriate evacuation areas in the event of large-scale flooding.

The total area of possible evacuation spaces for each building is estimated by the calculation of the "total floor area that is not inundated for each building" multiplied by the "possible percentage of evacuation spaces out of the total floor area." The total area of possible evacuation spaces is calculated by summing up these figures for each building.
The number of potential evacuees is calculated based on the total area of possible evacuation spaces, based on the assumption that the minimum space for each evacuee is $4 \mathrm{~m}^{2}$. The total number of potential evacuees from the inundated buildings is estimated to be 11,998 . When each building's use is examined, it is found that apartments as evacuation spaces for potential evacuees $(6,611)$ make up $55 \%$ of the total possible number of evacuees. Schools $(4,080)$ make up $34 \%$. Transportation facilities, office buildings, and commercial buildings account for $3 \%$ (378), 3\% (349), and 3\% (346), respectively.

\begin{tabular}{c|c}
\hline Building use & $\begin{array}{c}\text { Possible percentage of total } \\
\text { floor area }\end{array}$ \\
\hline $\begin{array}{c}\text { Schools, community } \\
\text { centers }\end{array}$ & $40 \%$ \\
\hline $\begin{array}{c}\text { Administrative } \\
\text { facilities }\end{array}$ & $20 \%$ \\
\hline Other public facilities & $0 \%$ \\
\hline Commercial buildings & $20 \%$ \\
\hline Office buildings & $5 \%$ \\
\hline Warehouses, stations & $5 \%$ \\
\hline Other industrial \\
buildings & $5 \%$ \\
\hline Apartment buildings & $5 \%$ (excluding their residents) \\
\hline Detached houses & $0 \%$ (excluding their residents) \\
\hline
\end{tabular}

Table 1. Possible percentage of total floor area based on building use

A look at the super levee area that is not inundated shows the number of potential evacuees in the area is around 8,355, which accounts for $70 \%$ of the total possible number of evacuees in an entire district.

\subsection{Adjusted number of evacuees}

The number of potential evacuees is adjusted based on the assumption that the people on the inundated floors evacuate to the upper floors of the same building, which results in a reduction in the number of potential evacuees in the same building and a reduction in the number of evacuation spaces for evacuees from the outside of the building. The number of people on the inundated floors who evacuate to the upper floors of the same building is estimated to be 718 at night and 387 in the daytime, in total.

Within an entire district, the adjusted number of evacuees is estimated to be 3,187 at night and 2,148 in the daytime. The adjusted number of potential evacuees is estimated to be 11,280 at night and 11,610 in the daytime. Excluding the evacuation spaces in the super levee area, the number of potential evacuees within an inundated area is estimated to be 2,925 at night and 3,256 in the daytime. 


\section{Conclusion}

In the event that the Arakawa River in Shinden district is breached, the number of estimated potential evacuees $(11,280)$ at night exceeds the number of estimated night-time evacuees $(3,187)$, and the number of estimated potential evacuees $(11,610)$ in the daytime exceeds the number of estimated daytime evacuees $(2,148)$ (Table 2). Therefore, it is possible for people in an inundated area to evacuate to safe places in the neighborhood on the condition that an appropriate evacuation system is established. In particular, it is important to make the most use of apartments that could be evacuation spaces.

However, the number of potential evacuees who can evacuate to safe spaces within an inundated area is only 2,925 at night and 3,256 in the daytime (Table 2). In particular, the number of estimated potential evacuees $(2,925)$ at night does not exceed the number of estimated night-time evacuees $(3,187)$. This means that neighborhood evacuation for each evacuee will be quite difficult, unless an upland area is created through such means as a super levee project. In other words, the super levee project has contributed to the creation of a largescale neighborhood evacuation area.

\begin{tabular}{c|c|c}
\hline Night & $\begin{array}{c}\text { Number of } \\
\text { estimated } \\
\text { evacuees }\end{array}$ & $\begin{array}{c}\text { Number of } \\
\text { estimated } \\
\text { potential evacuees }\end{array}$ \\
\hline Daytime & 3,187 & $\begin{array}{c}2,925 \\
11,280^{*}\end{array}$ \\
\hline
\end{tabular}

*Including a super levee area

Table 2. Number of estimated evacuees and potential evacuees.

The next research theme is to examine evacuation situations in greater detail, taking into consideration possible routes to the evacuation areas and the possibility of making use of private apartments or other private buildings as evacuation spaces.

\section{Acknowledgements}

This work was supported by JSPS KAKENHI Grant Number 15K06379.

\section{References}

1. The Cabinet Office (2010). Report by the expert committee in the Cabinet Office for considering measures against a large-scale flood (in Japanese)

2. Katada T., Kuwasawa N., Shida S., and Kojima M. (2013). Scenario analysis on evaluation strategies for residents in big cities during large-scale flood, Journal of Japan Society of Civil Engineers, B1 (Hydraulic Engineering), Vol.69, No.1, 71-82 (in Japanese)
3. The bureau of construction, the Tokyo Metropolitan Government (2016). River Improvement in Lowland Areas, http://www.kensetsu.metro.tokyo.jp/content/ 000000647.pdf. (accessed April 2016)

4. Nakamura H. and Kato T. (2013). Land use of super levees along the Arakawa River in the low-lying areas of Tokyo, Proceedings of the 12nd International Symposium on New Technologies for Urban Safety of Mega Cities in Asia (USMCA2013), A-7

5. Nakamura H., Shiozaki Y. and Kato T. (2013). Super levees along the Arakawa River in Tokyo, Evaluation from the viewpoint of spatial planning in a low-lying area, Extended summaries of the International Conference on Flood Resilience: Experiences in Asia and Europe (ICFR2013), 13-14

6. Nakamura H. and Kato T. (2014). Reevaluation of high standard levees along the Arakawa River as upland evacuation areas in the lowlands of Tokyo, Abstracts of the International Conference on Deltas in Times of Climate Change II, 105 